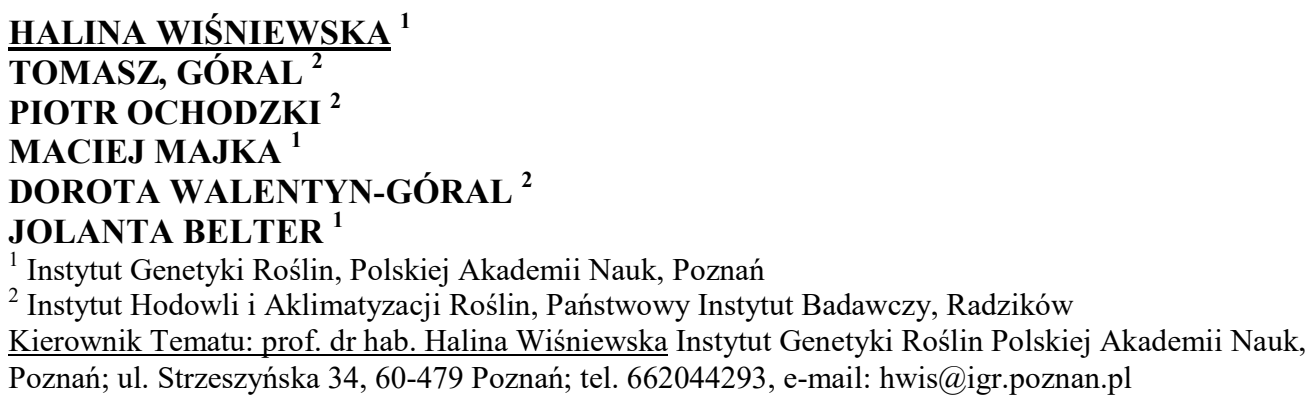

Prace zostały wykonane $w$ ramach badan podstawowych na rzecz postępu biologicznego w produkcji roślinnej na podstawie decyzji Ministra Rolnictwa $i$ Rozwoju Wsi nr HOR.hn.802.18.2018, Zadanie 14.

\title{
Badanie typów odporności na fuzariozę kłosów u pszenżyta ozimego za pomocą markerów fenotypowych i metabolicznych
}

\section{Evaluation of Fusarium head blight resistance types in winter triticale using phenotypic and metabolic markers}

Słowa kluczowe: gen $F h b 1$, fuzarioza kłosów, pszenżyto, mykotoksyny

\section{WPROWADZENIE}

Odmiany pszenżyta okazują się podatne na fuzariozę kłosów i kumulację w ziarnie toksyn fuzaryjnych. Głównym źródłem odporności jest locus cech ilościowych (QTL) Fhb1 zlokalizowany w krótkim ramieniu chromosomu 3BS, warunkuje wysoką odporność na fuzariozę - obecny w pszenicy Sumai 3. Scharakteryzowany jest również inny QTL - Fhb2 na 6BS. Ma on znacznie mniejszy wpływ na odporność. Podejmowane są próby poszerzenia zmienności pszenżyta przez wprowadzanie genów z gatunków oddalonych.

\section{CELE PROJEKTU}

— Badanie odporności typu I i II na fuzariozę kłosów u pszenżyta z wykorzystaniem markerów fenotypowych. 
- Identyfikacja molekularna genu $F h b 1$ mieszańców $\mathrm{BC}_{1}$ i BC$C_{2}$.

- Ocena odporności na uszkodzenie ziarna (typ III odporności).

- Określenie redukcji parametrów struktury plonu (typ IV odporności).

— Analiza zawartości toksyn fuzaryjnych w ziarniakach (typ V odporności).

\section{MATERIAŁY I METODY}

\section{Material badawczy}

Genotypy pszenżyta ozimego - temat badawczy 1, 2, 3 i 4 oraz linie pszenżyta $\mathrm{z}$ introgresją chromatyny Triticum monococcum i substytucjami genomu D pszenicy temat badawczy nr 1

\section{Metody badawcze}

— Testowanie metodą inokulacji (oprysk) w warunkach polowych oraz metodą inokulacji punktowej w Radzikowie i Cerekwicy.

- Badanie odporności na infekcję pierwotną (typ I odporności), na rozprzestrzenianie się patogenu wzdłuż osadki kłosowej (typ II odporności). Określanie indeksu fuzariozy kłosów (IFK) (połączone typy odporności I i II) — temat badawczy nr 1.

- Analizowanie odporności na uszkodzenie ziarniaków (typ III odporności) określanie wizualne proporcji ziarniaków uszkodzonych przez Fusarium (FDK) i ziarniaków wyglądających zdrowo (HLK) — temat badawczy nr 3.

- Określanie redukcji parametrów struktury plonu: (masy ziarna z kłosa (MZK), liczby ziarniaków w kłosie (LZK), masy tysiąca ziarniaków (MTZ), analiza tolerancji czyli odporności na obniżkę parametrów struktury plonu (typ IV odporności) - temat badawczy nr 3.

- Analiza zawartości toksyn fuzaryjnych w ziarniakach - deoksyniwalenolu (DON), niwalenolu (NIV), zearalenonu (ZEN) - chromatografia gazowa, (typ V odporność na kumulację/degradację toksyn fuzaryjnych) — temat badawczy nr 4.

- Identyfikowanie molekularne genu Fhb, 1 - temat badawczy 2.

\section{WYNIKI}

\section{Temat badawczy 1}

Doświadczenia infekcyjne w IHAR - PIB Radzików i IGR PAN Poznań z około 75 genotypami pszenżyta ozimego wybranymi jako formy o podwyższonej odporności w latach ubiegłych oraz z nowymi uzyskanymi na drodze krzyżowań z różnymi źródłami odporności

Brak opadów w okresie kwitnienia pszenżyta nie sprzyjał rozwojowi fuzariozy. W lokalizacji Cerekwica zastosowano po inokulacji zamgławianie, stąd porażenie kłosów było 3-krotnie wyższe $(8,7 \%)$ aniżeli w Radzikowie $(2,7 \%)$. Najniższe IFK poniżej 3,0\% odnotowano u 7 genotypów pszenżyta - DANKO 22 (2015), DANKO 6/15, DANKO 20/16, BOH 534-4, DS 1238, BOH 2271-4, MAH 34762-2.

Średnie IFK badanych linii pszenżyta z introgresją chromatyny $T$. monococcum i substytucjami genomu D pszenicy wynosiło $6,8 \%$, porażenie do $4 \%$ odnotowano u 8 linii. 
Średnia liczba punktów infekcji (typ I odporności) dla 49 genotypów pszenżyta wynosiła 1,9. Najwyższą odporność typu I odnotowano dla genotypów DC 06080-56, BOHD 898-1, MAHD 33404-1, DC 03326/06/2, DS. 9, DANKO 17 (2014), BOHD 1025-2 i MAH 35657-2.

Średnia liczba porażonych kłosków (typ II odporności) dla 49 badanych genotypów wynosiła 2. Najwyższą odporność typu II zanotowano dla genotypów MAH 33544-3, BOH 835-4, DANKO 2 (2014), DANKO 21 (2015), BOH 1062-2, DANKO 10 (2015). Średnia odporność obu typów odporności była najwyższa u genotypów MAH 33544-3, DS. 9, DC 06080-56, DL 593/07, MAH 34359-1 i BOHD 1025-2. Średnia odporność typu I i II korelowała istotnie z IFK w obu lokalizacjach oraz ze średnim IFK.

Temat badawczy 2

Doświadczenia infekcyjne $w$ dodatkowych lokalizacjach. Krzyżowanie wybranych genotypów pszenżyta, rozmnażanie uzyskanych mieszańców

Inokulacja pszenżyta przeprowadzona w lokalizacjach Dębina, Borowo, Małyszyn i Szelejewo wykazała wystąpienie porażenia kłosów tylko w Dębinie. Średni \%IFK z lokalizacji Cerekwica i Radzikowo korelował z IFK w Dębinie $(\mathrm{r}=0,430)$.

Formy mieszańcowe $\mathrm{BC}_{1}$ i $\mathrm{BC}_{2}$ niosące gen odporności na fuzariozę kłosa $F h b 1$, zostały poddane krzyżowaniom wstecznym $\mathrm{w}$ celu otrzymania mieszańców pokolenia $\mathrm{BC}_{2} \mathrm{i} \mathrm{BC}_{3}$. Uzyskano 11 form $\mathrm{BC}_{2} \mathrm{z}$ genem odporności $F h b 1$ oraz 56 form $\mathrm{BC}_{3}$.

\section{Temat badawczy 3}

Analiza zebranego materiału pod kątem oceny odporności na uszkodzenie ziarniaków (typ III)

Prażenie ziarna było zróżnicowane. Średni procent FDK masa w Cerekwicy wynosił 11,39\% natomiast FDK liczba 18,55\%. Dla genotypów ocenionych w Radzikowie średni procent FDK masa wynosił 14,18\%, a FDK liczba 14,80\%. Najniższą liczbę porażonego ziarna (FDK liczba) odnotowano u genotypu DS.9.

IFK w Poznaniu korelował istotnie $\mathrm{z}$ wartościami FDK w Poznaniu i ze średnimi FDK. Podobne były zależności IFK i FDK w Radzikowie. Średnia wartość IFK korelowała z wartościami średnimi FDK masa i FDK liczba.

Średnio najniższą redukcję MZK odnotowano u genotypów MAH 34068-5 (S), DANKO 3/15, MAH 33115-4/1 i DANKO 2/16. Najniższa średnia redukcja MTZ wystąpiła u genotypów BOHD 2027-1, DANKO 3/17, DS. 9, DANKO 13/17 i DANKO 28/17.

IFK korelował z uszkodzeniem ziarniaków. Uszkodzenie ziarniaków (FDK masa i FDK liczba) korelowało z względną redukcją MTZ.

\section{Temat badawczy 4}

Analiza w badanym materiale zawartości toksyn fuzaryjnych w ziarnie, kumulacja/degradacja toksyn (typ V odporności)

We wszystkich próbach ziarna stwierdzono obecność DON, NIV oraz pochodnej acetylowej 3Ac-DON. Brak było 15Ac-DON, a pochodna 3Ac-DON występowała w ilościach śladowych.

W Poznaniu dominował NIV — zawartość ponad 10-krotnie wyższa niż DON-u. W Radzikowie natomiast dominował DON (30-krotnie więcej NIV) (rys. 1). 
Box plots

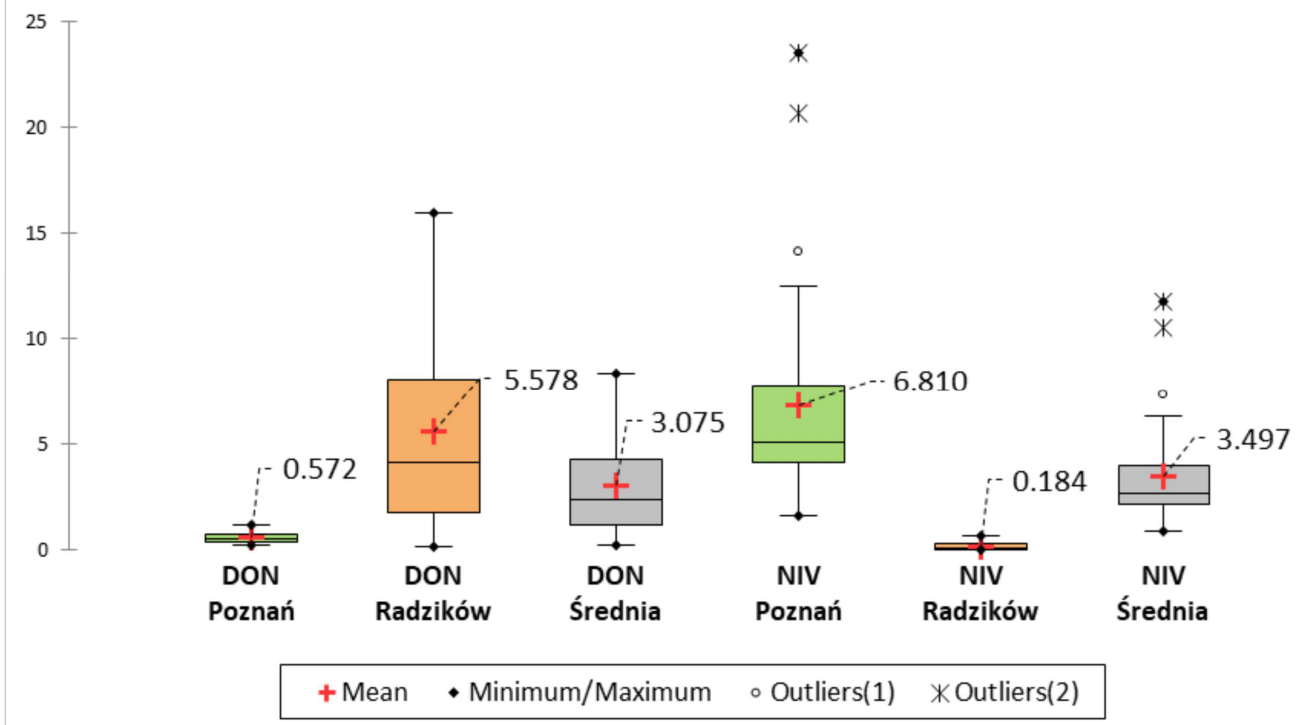

Rys. 1. Porównanie zawartości DON i NIV w próbach ziarna 39 genotypów pszenżyta pochodzących

z Poznania i Radzikowa. Prostokąty pokazują pierwszy kwartyl, medianę i trzeci kwartyl. Wąsy pokazują dolny i górny limit, poza którym wartości są odstające

Najniższe zawartości DON stwierdzono u genotypów LD 121/08, MAHD 35399-1, BOH 534-4, DANKO 2/17, MAH 34359-1, BOHD 898-1 i odmiany Trefl. Natomiast najniższe zawartości NIV stwierdzono u genotypów DS. 9, BOH 537-2, DANKO 3/17, BOHD 898-1. Sumarycznie najmniej trichotecenów B było w ziarnie genotypów BOHD 898-1, DANKO 3/17, DS. 9, DC 03326/06/2, Trefl, BOHD 1025-2 i MAHD 35399-1.

Zawartość ZEN w ziarnie wynosiła średnio $94 \mu \mathrm{g} / \mathrm{kg}$. W próbach ziarna z Radzikowa było go około 5-krotnie więcej niż w próbach ziarna z Cerekwicy. Najmniej ZEN było w ziarnie genotypów BOH 534-4, MAH 34359-1, BOHD 898-1, DANKO 2/17, LD 121/08, MAHD 35399-1 i DS. 9. IFK korelował z zawartością NIV i sumaryczną zawartością trichotecenów $\mathrm{B}$, nie stwierdzono korelacji $\mathrm{z}$ zawartością DON i ZEN. Poziom uszkodzenia ziarniaków korelował z zawartością wszystkich badanych mykotoksyn.

Stwierdzono istotne ujemne współczynniki korelacji MTZ oraz DON, ZEN i sumy trichotecenów B.

\section{PODSUMOWANIE}

Analiza wieloczynnikowa pozwoliła na zidentyfikowanie genotypów łączących odporności różnych typów. Są to DS. 9, BOHD 898-1, odmiana Trefl, DANKO 2/17, DANKO 3/17, BOH 534-4, MAHD 35399-1, DL 593/07, DC 03326/06/2, LD 121/08, 
BOHD 1025-2, odmiana Meloman, BOH 537-2 i DANKO 22/17. Cztery z nich to nowe genotypy pochodzące w Doświadczenia Wstępnego 2017/2018 (rys. 2).

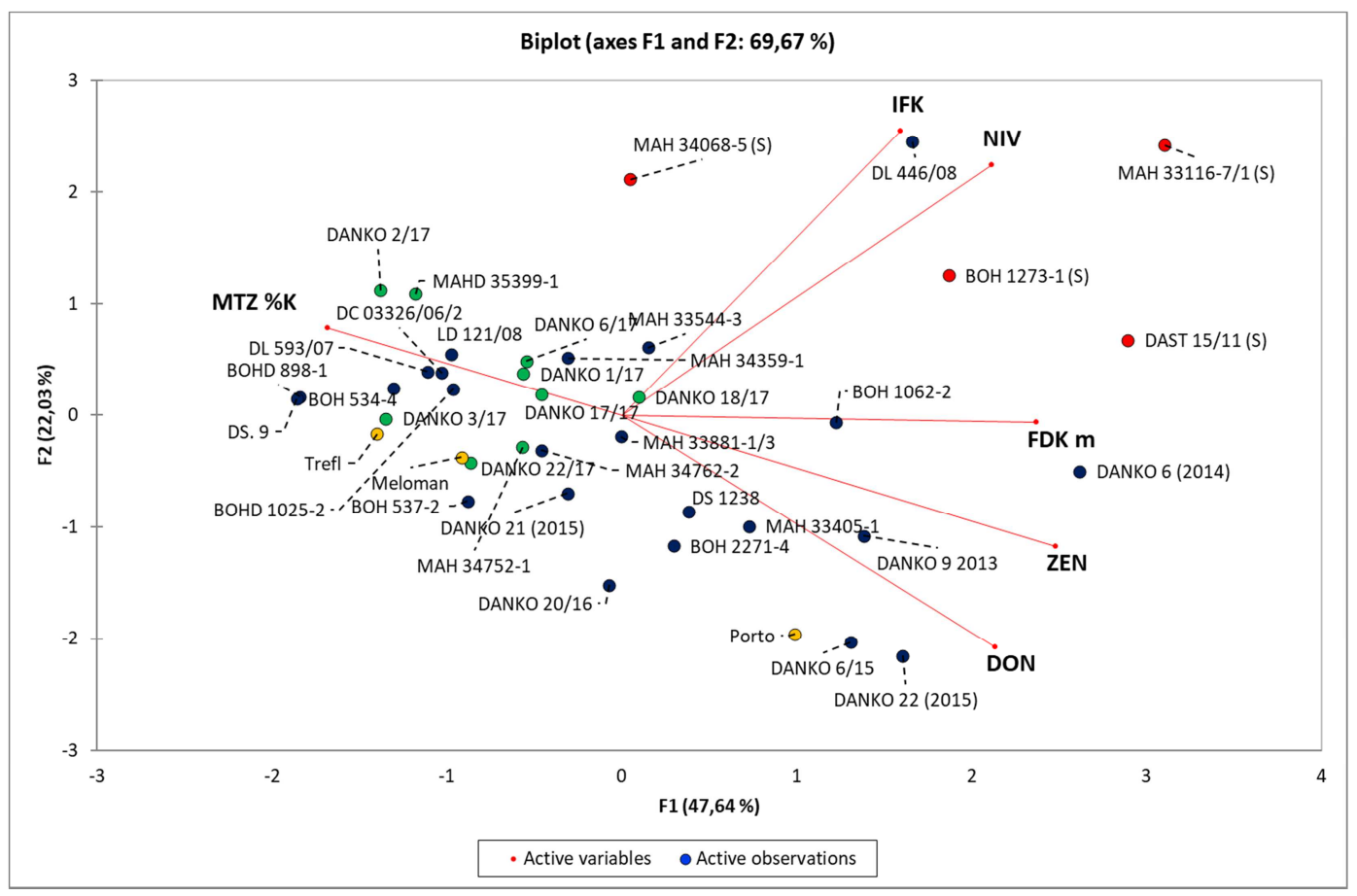

Rys. 2. Układ współrzędnych dwóch pierwszych składowych głównych dla 39 genotypów pszenżyta ozimego. Składowe wyjaśniają 69,67\% zmienności odporności na fuzariozę kłosów mierzoną indeksem fuzariozy kłosów (IFK), stopniem uszkodzenia ziarniaków (FDK m), względną wartością MTZ (\% kontroli) oraz zawartością toksyn fuzaryjnych (deoksyniwalenolu [DON] niwalenolu [NIV] oraz zearalenonu [ZEN]) w ziarnie. Wektory wskazują kierunek wzrostu wartości zmiennych. Na zielono zaznaczono genotypy z DW 17/18, na czerwono wzorce podatne 
